\title{
Influence of age and gender on the epidemic of COVID-19
}

\section{Evidence from 177 countries and territories - an exploratory, ecological study}

\author{
Dingtao Hu $\cdot$ Xiaoqi Lou $\cdot$ Nana Meng $\cdot$ Zhen Li $\cdot$ Ying Teng $\cdot$ Yanfeng Zou $\cdot$ Fang Wang
}

Received: 29 August 2020 / Accepted: 13 January 2021 / Published online: 5 February 2021

(c) Springer-Verlag GmbH, AT part of Springer Nature 2021

\begin{abstract}
Summary
Background The pandemic of coronavirus disease 2019 (COVID-19) is spreading worldwide with an uncertain ultimate impact on every aspect of human society. Recognizing the groups with higher susceptibility and fatality are in urgent need.

Methods We retrieved the total number of confirmed incident and death cases of COVID-19 in 177 countries/territories from the Center for Systems Science and Engineering (CSSE) at Johns Hopkins University (JHU). Data of age and gender composition were collected from the United Nations Department of Economic and Social Affairs. Spearman's correlation analysis was used to explore the association between the composition of age and gender and the incidence rate (IRC), case fatality rate (CFRC), and mortality rate of COVID-19 (MRC). Multiple comparisons were adjusted by the Bonferroni method, and the threshold $p$-value was set as $p<0.01$. Software SPSS 23.0, ArcGIS
\end{abstract}

Dingtao Hu and Xiaoqi Lou contributed equally to this work and should be considered as co-first authors.

Data availability statement Data is available to authorized users.

\footnotetext{
Role of the funder/sponsor This work was supported by the grant from the National Natural Science Foundation of China (grant numbers 81602115, 81872683), the Foundation of Supporting Program for the Excellent Young Faculties in University of Anhui Province in China (grant number gxyq2019012), Grants for Scientific Research of BSKY from the First Affiliated Hospital of Anhui Medical University and Grants for Outstanding Youth from the First Affiliated Hospital of Anhui Medical University. The funders had no role in the design and conduct of the study; collection, management, analysis, and interpretation of the data; preparation, review, or approval of the manuscript; and decision to submit the manuscript for publication.
}

10.6, and GraphPad Prism 8.0 were used to generate our results.

Results Median age was positively correlated to IRC, CFRC and MRC $\left(r_{s}=0.60 ; r_{s}=0.27 ; r_{s}=0.61, p<0.0001\right.$ for all). The age-dependent correlation between people over 65 years of age with IRC was higher in females, while the correlation between age distribution and CFRC as well as MRC was higher in males $(p<0.0001$ for all). Besides, we found the age-gender-dependent differences were correlated to IRC in places with high income and associated with CFRC in non-high income countries/territories.

Conclusion The correlation between the composition of age and gender and the epidemic characteristics of COVID-19 confirmed previous points that females are more susceptible to COVID-19. The results remind us that more attention should be paid to male patients, particularly those over 65 years old for enhanced clinical management. 
Keywords Incidence rate - Case fatality rate Mortality rate $\cdot$ Correlation analysis · Coronavirus disease 2019

\section{Introduction}

In recent years, the outbreak and unpredictable transmission scale of infectious diseases have put tremendous threats on public health and safety, from the severe acute respiratory syndrome (SARS) in 2002, the influenza $\mathrm{H} 1 \mathrm{~N} 1$ in 2009, and Middle East respiratory syndrome (MERS) in 2012 [1-3]. In late December 2019, a series of pneumonia cases caused by a new virus, which was defined as severe acute respiratory syndrome coronavirus 2 (SARS-CoV-2) were reported; the diseases were named coronavirus disease 2019 (COVID-19) on 11 February 2020, subsequently [4]. As of 31 May 2020, the storm-like virus had spread across 188 countries and territories, resulting in over $5,000,000$ confirmed infections and 370,000 deaths [5]. Recognizing the group with higher susceptibility and fatality, taking more effective surveillance and targeted interventions help minimize the epidemic's adverse effects, and assist in the ultimate control of COVID-19. Based on the hospital data, earlier epidemiological studies showed that age and gender are two of the most important factors that influence the susceptibility and severity of COVID-19 [6-8]; however, only China and a few other countries had provided surveillance data of patients with COVID19, including age and sex [9]. Little is known whether the reported age-gender-dependent patterns exist in other countries and territories. Besides, most previous studies focused on the composition of gender and age among COVID-19 patients, the relationship between the age and gender composition of the entire society and the prevalence of COVID-19 remains unclear.

In the current research, we aimed to explore the association between the composition of age and gender among the whole population and the epidemic characteristics COVID-19 globally, provide guides for the targeted intervention and the establishment of risk stratification for all patients infected with SARSCoV-2.

\section{Methods}

\section{Data sources}

The data of the epidemic characteristics of COVID-19, including the total number of infected cases (TC) and the total number of deaths (TD) in 188 countries and territories, were downloaded from the Center for Systems Science and Engineering (CSSE) at Johns Hopkins University (JHU) on 31 May 2020 [5]. The data of age and gender composition were downloaded from the publicly available website of the United Nations Department of Economic and Social Affairs [10].

\section{Variables of analysis}

To analyze the association between gender and the epidemic of COVID-19, the sex ratio of the total population (males per 100 females, SROTP) in various countries and territories was included. We grouped the total population into three age groups: $0-24$ years (percentage of total population, both sexes combined, by broad age group, 0-24 years, (PTPbscbag, 0-24)), 25-64 years (PTPbscbag, 25-64), and 65+ years (PTPbscbag, 65+). Also, we retrieved the distribution of age in female and male populations: percentage of female population by broad age group (PFPbag), and percentage of male population by broad age group (PMPbag). The male and female populations were also divided into three groups: 0-24 years, 25-64 years, and $65+$ years. The median age of the total population was also analyzed in the current study. Besides, considering the wide variation of the total population in different countries and territories, which might be a risk of bias to our research, we calculated the incidence rate of COVID-19 (IRC), the case fatality rate of COVID-19 (CFRC), and the mortality rate of COVID-19 (MRC) in the current research, which could better reflect the influence of age and gender on the epidemic of COVID-19. Those variables were presented in Table S1.

\section{Regional distribution of analysis}

There are 11 countries/territories that were excluded from the current research: Andorra, San Marino, Monaco, Holly See, Liechtenstein, St. Kitts \& Nevis, Dominica, Diamond Princess, West Bank and Gaza, Kosovo, and MS Zaandam, since the data of age and gender are not available in these places. To further explore the correlations between age, gender, and the epidemic of COVID-19 pandemic, we divided these 177 countries/territories into 4 continents/regions: Europe, Americas (including North America and South America), Asia and Oceania, and Africa. Since there are only four countries (Papua New Guinea, Fiji, Australia, and New Zealand) in Oceania that were contained in our study, we grouped the countries in Oceania and territories in Asia into one group (Asia and Oceania) to implement our analysis. We also separated the 177 places into 2 groups: the high income and non-high income countries/ territories, to figure out whether the age-gender-dependent association with the epidemic of COVID-19 is similar in places with different economic development. According to the World Bank, the former group contains the countries/territories with the gross national income per capita (GNIPC) over $\$ 12,376$, while the latter contains the remaining places [11]. 


\section{Statistical analysis}

We implemented a correlation analysis to explore the association between the age and gender composition (SROTP, males per 100 females), median age, PTPbscbag (0-24, 25-64, 65+), PFPbag (0-24, 25-64, 65+), and PMPbag (0-24, 25-64, 65+), and the epidemic characteristics of COVID-19 (TC, TD, IRC, CFRC, and MRC) in 177 countries and territories. Statistical analysis was conducted using software SPSS version 23.0 (IBM, Armonk, NY, USA). In the current study, each indicator of age and gender composition was compared with five epidemic characteristics of COVID-19. To control the type I error because of the multiple comparisons, the Bonferroni correction was used, and the threshold $p$-value was set as $p<0.01$ $(0.05 / 5)$. Besides, all other $p$-values are to be interpreted in an exploratory manner, and GraphPad Prism 8.2 (Graphpad Inc, Harvey Motulsky, USA) and ArcGIS 10.6 (ESRI Inc, Jack Dangermond, Redlands, CA, USA) were used to generate figures.

\section{Results}

Correlations between the composition of age and gender and the epidemic characteristics of COVID19 in 177 countries/territories

Table 1 presents the correlations among the composition of age and gender and the epidemic characteristics of COVID-19. We found that median age was positively correlated to TC, TD, IRC, MRC $\left(r_{s}=0.41\right.$, $r_{s}=0.43, r_{s}=0.60, r_{s}=0.61$, respectively, $p<0.0001$ for all), and CFRC $\left(r_{s}=0.27, p<0.001\right)$. Negative correlations were found between the TC $\left(r_{s}=-0.43, r_{s}=-0.43\right.$, $r_{s}=-0.40$, respectively) and PTPbscbag (0-24), PMPbag $(0-24)$, PFPbag $(0-24)$, between TD $\left(r_{s}=-0.42, r_{s}=-0.41\right.$, $r_{s}=-0.42$, respectively) and PTPbscbag (0-24), PMPbag
(0-24), PFPbag (0-24), between IRC $\left(r_{s}=-0.62, r_{s}=-0.64\right.$, $r_{s}=-0.58$, respectively) and PTPbscbag (0-24), PMPbag $(0-24)$, PFPbag (0-24), and between MRC $\left(r_{s}=-0.61\right.$, $r_{s}=-0.60, r_{s}=-0.60$, respectively) and PTPbscbag $(0-24)$ PMPbag ( $0-24)$, PFPbag $(0-24)(p<0.0001$ for all). On the contrary, positively correlations were detected between TC $\left(r_{s}=0.35, r_{s}=0.36, r_{s}=0.33\right.$, respectively, $p<0.0001$ for all) and PTPbscbag (25-64), PMPbag (25-64), PFPbag (25-64), between TD $\left(r_{s}=0.30, p<\right.$ $0.0001 ; r_{s}=0.31, \quad p<0.0001 ; \quad r_{s}=0.28, \quad p<0.001$, respectively) and PTPbscbag (25-64), PMPbag (25-64), PFPbag (25-64), between IRC $\left(r_{s}=0.57, r_{s}=0.59, r_{s}=0.53\right.$, respectively, $p<0.0001$ for all) and PTPbscbag (25-64), PMPbag (25-64), PFPbag (25-64), and between MRC $\left(r_{s}=0.49, r_{s}=0.51, r_{s}=0.47\right.$, respectively, $p<0.0001$ for all) and PTPbscbag (25-64), PMPbag (25-64), PFPbag (25-64). Also, we observed strongly positive correlations between TC $\left(r_{s}=0.36, r_{s}=0.37, r_{s}=0.35\right.$, respectively) and PTPbscbag (65+), PMPbag (65+), PFPbag $(65+)$, between TD $\left(r_{s}=0.43, r_{s}=0.45, r_{s}=0.42\right.$, respectively) and PTPbscbag (65+), PMPbag (65+), PFPbag $(65+)$, between IRC $\left(r_{s}=0.50, r_{s}=0.51, r_{s}=0.51\right.$, respectively) and PTPbscbag (65+), PMPbag (65+), PFPbag $(65+)$, and between MRC $\left(r_{s}=0.58, r_{s}=0.59, r_{s}=0.57\right.$, respectively) and PTPbscbag (65+), PMPbag (65+), PFPbag $(65+)(p<0.0001$ for all). Interestingly, compared with the male group, we found a relatively lower correlation between MRC and PFPbag (65+) in the female group (male: 0.59, female: 0.57 ).

Besides, CSRC was found negatively correlated to PTPbscbag (0-24) $\left(r_{s}=-0.22, p=0.003\right)$, and PFPbag $(0-24)\left(r_{s}=-0.26, p=0.001\right)$. No correlations were detected between PTPbscbag (25-64), PMPbag (25-64), PFPbag (25-64), and CFRC ( $p>0.01$ for all). Instead, positively correlations were observed for PTPbscbag (65+), PMPbag (65+), PFPbag (65+) and CFRC ( $r_{s}=0.34$, $r_{s}=0.37, r_{s}=0.31$, respectively, $p<0.0001$ for all). Interestingly, the correlation between CFRC and the ratio

Table 1 Correlation between composition of age and gender in 177 countries/territories and epidemic characteristics of COVID-19

\begin{tabular}{|c|c|c|c|c|c|c|c|c|c|c|c|}
\hline \multirow{2}{*}{\multicolumn{2}{|c|}{$\begin{array}{l}\text { Composition of age and } \\
\text { gender }\end{array}$}} & \multicolumn{2}{|c|}{$\begin{array}{l}\text { Total number of } \\
\text { cases }\end{array}$} & \multicolumn{2}{|c|}{$\begin{array}{l}\text { Total number of } \\
\text { deaths }\end{array}$} & \multicolumn{2}{|c|}{$\begin{array}{l}\text { Incidence rate of } \\
\text { COVID-19 }\end{array}$} & \multicolumn{2}{|c|}{$\begin{array}{l}\text { Case fatality rate of } \\
\text { COVID-19 }\end{array}$} & \multicolumn{2}{|c|}{$\begin{array}{l}\text { Mortality rate of } \\
\text { COVID-19 }\end{array}$} \\
\hline & & $R_{S}$ & $p$ & $R_{S}$ & $p$ & $R_{S}$ & $p$ & $R_{S}$ & $p$ & $R_{S}$ & $p$ \\
\hline \multicolumn{2}{|c|}{$\begin{array}{l}\text { SROTP (males per } 100 \\
\text { females) }\end{array}$} & -0.03 & 0.658 & -0.09 & 0.229 & -0.03 & 0.677 & -0.18 & 0.017 & -0.15 & 0.051 \\
\hline \multicolumn{2}{|l|}{ Median age } & 0.41 & $<0.0001$ & 0.43 & $<0.0001$ & 0.60 & $<0.0001$ & 0.27 & $<0.001$ & 0.61 & $<0.0001$ \\
\hline \multirow[t]{3}{*}{ PTPbscbag } & $0-24$ & -0.43 & $<0.0001$ & -0.42 & $<0.0001$ & -0.62 & $<0.0001$ & -0.22 & 0.003 & -0.61 & $<0.0001$ \\
\hline & $25-64$ & 0.35 & $<0.0001$ & 0.30 & $<0.0001$ & 0.57 & $<0.0001$ & 0.08 & 0.299 & 0.49 & $<0.0001$ \\
\hline & $65+$ & 0.36 & $<0.0001$ & 0.43 & $<0.0001$ & 0.50 & $<0.0001$ & 0.34 & $<0.0001$ & 0.58 & $<0.0001$ \\
\hline \multirow[t]{3}{*}{ PMPbag } & $0-24$ & -0.43 & $<0.0001$ & -0.41 & $<0.0001$ & -0.64 & $<0.0001$ & -0.19 & 0.010 & -0.60 & $<0.0001$ \\
\hline & $25-64$ & 0.36 & $<0.0001$ & 0.31 & $<0.0001$ & 0.59 & $<0.0001$ & 0.09 & 0.227 & 0.51 & $<0.0001$ \\
\hline & $65+$ & 0.37 & $<0.0001$ & 0.45 & $<0.0001$ & 0.51 & $<0.0001$ & 0.37 & $<0.0001$ & 0.59 & $<0.0001$ \\
\hline \multirow[t]{3}{*}{ PFPbag } & $0-24$ & -0.40 & $<0.0001$ & -0.42 & $<0.0001$ & -0.58 & $<0.0001$ & -0.26 & 0.001 & -0.59 & $<0.0001$ \\
\hline & $25-64$ & 0.33 & $<0.0001$ & 0.28 & $<0.001$ & 0.53 & $<0.0001$ & 0.09 & 0.234 & 0.47 & $<0.0001$ \\
\hline & $65+$ & 0.35 & $<0.0001$ & 0.42 & $<0.0001$ & 0.51 & $<0.0001$ & 0.31 & $<0.0001$ & 0.57 & $<0.0001$ \\
\hline
\end{tabular}

COVID-19 coronavirus disease 2019, SROTP sex ratio of the total population, PTPbscbag percentage of total population, both sexes combined, by broad age group, PMPbag percentage of male population by broad age group, PFPbag percentage of female population by broad age group 


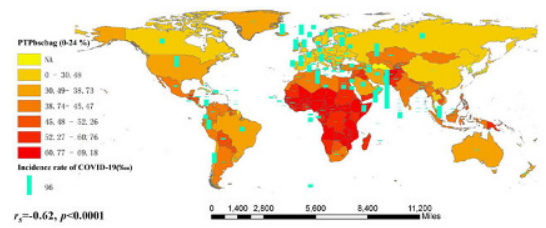

a

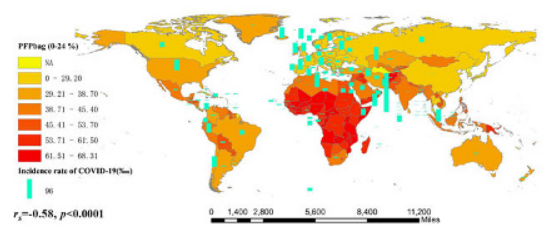

d

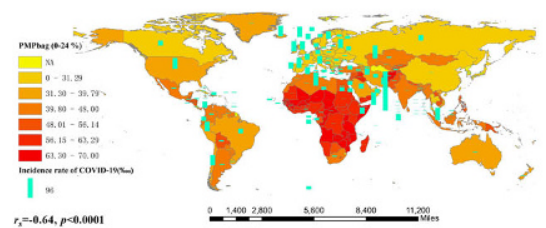

g

Fig. 1 Graph map of the incidence rate of COVID-19 and age distribution of the total population $(\mathbf{a}-\mathbf{c})$, the female population (d-f), and the male population ( $(\mathbf{g}-\mathbf{i})$ (the height of the straight bar in various countries and territories represents the incidence rate of COVID-19, the higher the bar, the higher the

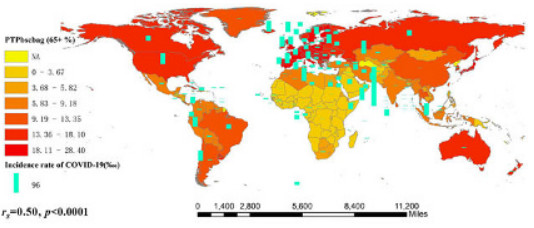

C

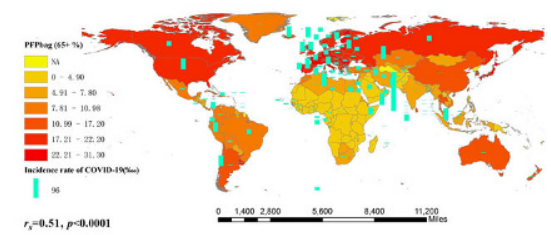

f

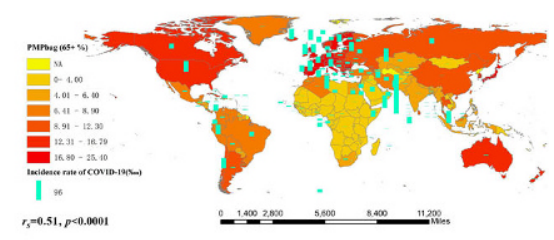

i

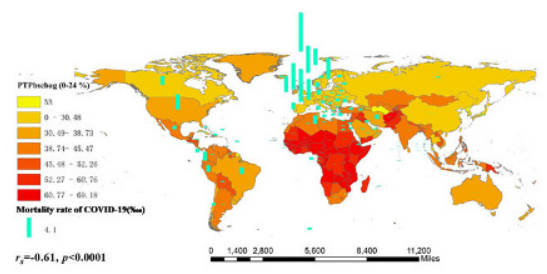

a

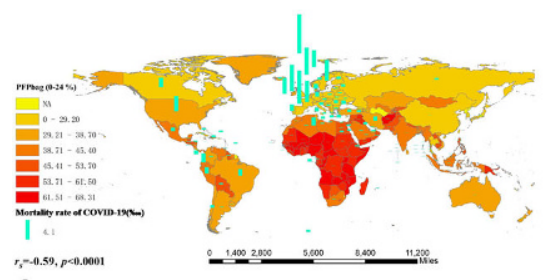

d

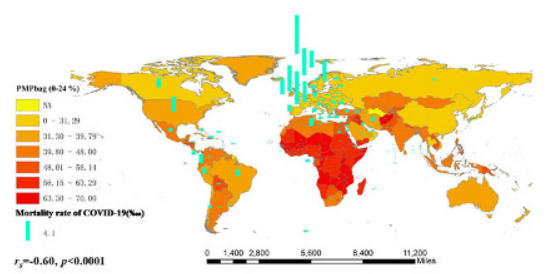

g

Fig. 2 Graph map of the mortality rate of COVID-19 and age distribution of the total population (a-c), the female population (d-f), and the male population (g-i) (the height of the straight bar in various countries and territories represents the mortality rate of COVID-19, the higher the bar, the higher the mortality

b

h incidence rate). PTPbscbag percentage of total population, both sexes combined, by broad age group, PMPbag percentage of male population by broad age group, PFPbag percentage of female population by broad age group
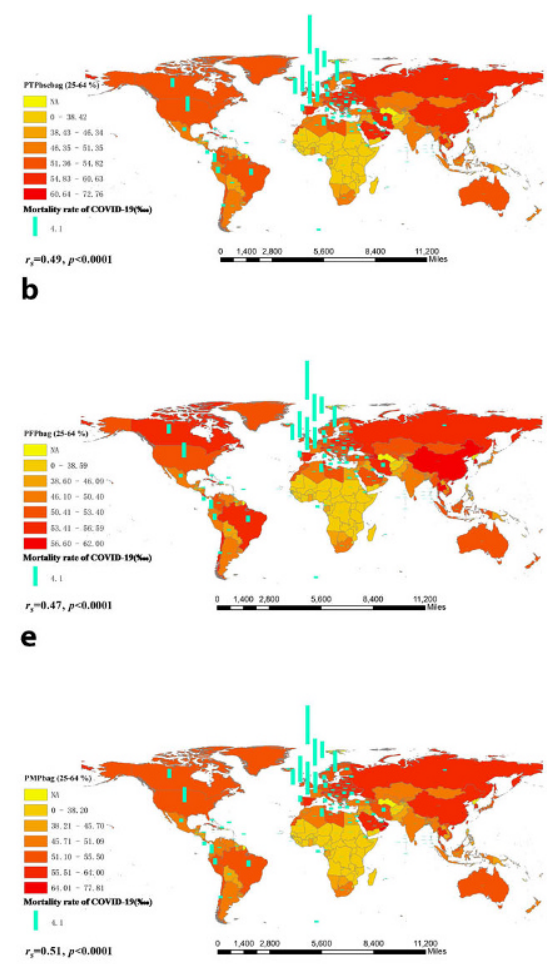

rate). PTPbscbag percentage of total population, both sexes combined, by broad age group, PMPbag percentage of male population by broad age group, PFPbag percentage of female population by broad age group 


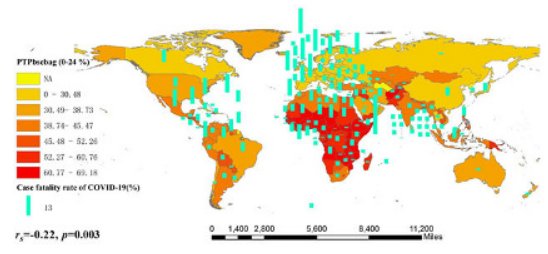

a

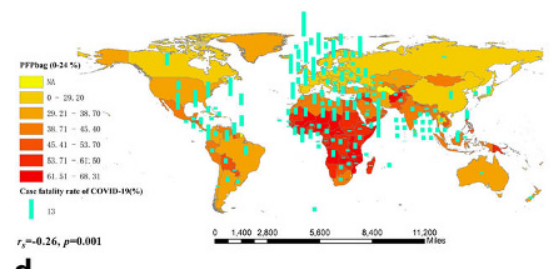

d

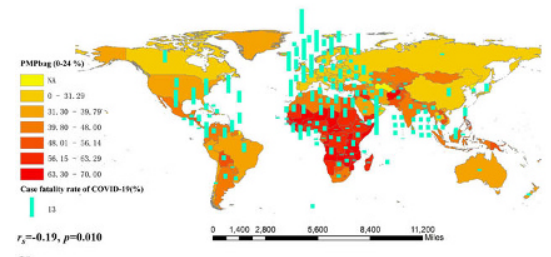

g

Fig. 3 Graph map of the case fatality rate of COVID-19 and age distribution of the total population (a-c), the female population $(\mathbf{d}-\mathbf{f})$, and the male population $(\mathbf{g}-\mathbf{i})$ (the height of the straight bar in various countries and territories represents the case fatality rate of COVID-19, the higher the bar, the higher

of people over 65 years old among the female group was also lower compared with the male group (male: 0.37 , female: 0.31 ). To visually presenting the influence of age and gender on the epidemic of COVID19, the graph of the composition of age and gender, and IRC, MRC, CFRC in 177 countries/territories were performed in Figs. 1, 2 and 3.

As shown in Fig. 1, places with a higher group of younger individuals (aged 0-24) had a lower incidence rate of COVID-19, while the remarkabl high IRC was noticed in places with a high group of people over 25 years (aged 25-64, 65+). Similar observations were also found in the association between the composition of age and gender and MRC. The higher mortality rate of COVID-19 was noticed in places with a higher group of people over 25 years (aged 25-64, 65+), and lower MRC was found in places with a higher group of juniors (aged 0-24) (Fig. 2). Besides, a higher CFRC was detected in places with a higher group of old people (aged 65+) and places with a higher ratio of juniors (aged 0-24) presented with lower CFRC (Fig. 3). Moreover, such phenomena were observed in both male and female groups.

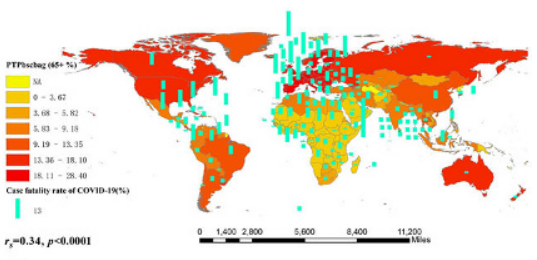

C
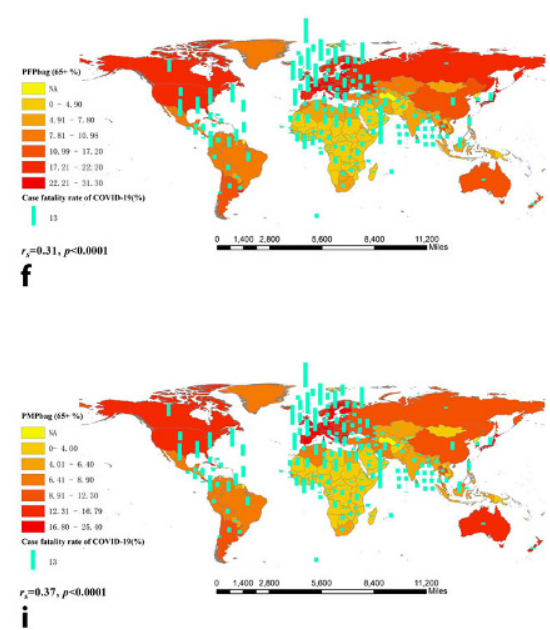

the case fatality rate). PTPbscbag percentage of total population, both sexes combined, by broad age group, PMPbag percentage of male population by broad age group, PFPbag percentage of female population by broad age group

Correlations between the composition of age and gender and the epidemic characteristics of COVID19 in various continents/regions

Table 2 lists the associations between the composition of age, gender, and the epidemic characteristics of COVID-19 in Europe, Africa, Asia and Oceania, and Americas. In Europe, no correlations exist between SROTP (males per 100 females) and all the epidemic characteristics of COVID-19 ( $p>0.01$ for all), while the median age of the total population was only positively correlated to CFRC $\left(r_{s}=0.45\right.$, $p=0.003)$. Significant correlation was detected between PTPbscbag (65+) and CFRC $\left(r_{s}=0.43, p=0.005\right)$. In the male group, we discovered that PMPbag (65+) was positively correlated to CFRC, with the correlation coefficient as $0.55(p<0.001)$. Among the female population, no significant correlation was detected ( $p>0.01$ for all). In Africa, we found lower positive correlations between SROTP (males per 100 females) and MRC ( $\left.r_{s}=0.36, p=0.007\right)$, as well as between the median age and IRC $\left(r_{s}=0.35, p=0.008\right)$. IRC was also found positively correlated to PTPbscbag (25-64), with the correlation coefficient as $0.36(p=0.008)$. In Asia and Oceania, we found that SROTP (males per 100 females) was positively correlated to TC $\left(r_{s}=0.31\right.$, $p=0.032)$, IRC $\left(r_{s}=0.44, p=0.002\right)$, and MRC $\left(r_{s}=0.34\right.$, $p=0.005)$. Additionally, IRC and MRC were negatively 
Table 2 Correlation between composition of age and gender in various continents/regions and epidemic characteristics of COVID-19

\begin{tabular}{|c|c|c|c|c|c|c|c|c|c|c|c|c|}
\hline \multirow[t]{2}{*}{$\begin{array}{l}\text { Continents/ } \\
\text { Regions }\end{array}$} & \multirow{2}{*}{\multicolumn{2}{|c|}{ Composition of age and gender }} & \multicolumn{2}{|c|}{$\begin{array}{l}\text { Total number of } \\
\text { cases }\end{array}$} & \multicolumn{2}{|c|}{$\begin{array}{l}\text { Total number of } \\
\text { deaths }\end{array}$} & \multicolumn{2}{|c|}{$\begin{array}{l}\text { Incidence rate of } \\
\text { COVID-19 }\end{array}$} & \multicolumn{2}{|c|}{$\begin{array}{l}\text { Case fatality rate of } \\
\text { COVID-19 }\end{array}$} & \multicolumn{2}{|c|}{$\begin{array}{l}\text { Mortality rate of } \\
\text { COVID-19 }\end{array}$} \\
\hline & & & $R_{S}$ & $p$ & $R_{S}$ & $p$ & $R_{S}$ & $p$ & $R_{S}$ & $p$ & $R_{S}$ & $p$ \\
\hline \multirow[t]{11}{*}{ Europe } & \multicolumn{2}{|c|}{ SROTP (males per 100 females) } & -0.15 & 0.344 & -0.09 & 0.585 & 0.24 & 0.139 & 0.10 & 0.540 & 0.20 & 0.200 \\
\hline & \multicolumn{2}{|l|}{ Median age } & 0.15 & 0.344 & 0.26 & 0.095 & -0.18 & 0.258 & 0.45 & 0.003 & 0.18 & 0.258 \\
\hline & \multirow[t]{3}{*}{ PTPbscbag } & $0-24$ & -0.03 & 0.852 & -0.10 & 0.549 & 0.28 & 0.078 & -0.18 & 0.269 & 0.05 & 0.766 \\
\hline & & $25-64$ & -0.08 & 0.635 & -0.16 & 0.329 & -0.16 & 0.334 & -0.32 & 0.040 & -0.24 & 0.127 \\
\hline & & $65+$ & 0.10 & 0.548 & 0.21 & 0.181 & -0.16 & 0.313 & 0.43 & 0.005 & 0.15 & 0.345 \\
\hline & \multirow[t]{3}{*}{ PMPbag } & $0-24$ & -0.02 & 0.894 & -0.11 & 0.486 & 0.25 & 0.120 & -0.26 & 0.095 & -0.04 & 0.809 \\
\hline & & $25-64$ & -0.17 & 0.295 & -0.23 & 0.150 & -0.29 & 0.063 & -0.30 & 0.055 & -0.34 & 0.031 \\
\hline & & $65+$ & 0.26 & 0.095 & 0.39 & 0.011 & 0.08 & 0.626 & 0.55 & $<0.001$ & 0.40 & 0.010 \\
\hline & \multirow[t]{3}{*}{ PFPbag } & $0-24$ & -0.04 & 0.817 & -0.08 & 0.620 & 0.31 & 0.046 & -0.14 & 0.391 & 0.11 & 0.515 \\
\hline & & $25-64$ & -0.07 & 0.652 & -0.16 & 0.324 & -0.09 & 0.572 & -0.37 & 0.019 & -0.24 & 0.139 \\
\hline & & $65+$ & 0.03 & 0.874 & 0.13 & 0.430 & -0.25 & 0.113 & 0.34 & 0.029 & 0.05 & 0.781 \\
\hline \multirow[t]{11}{*}{ Africa } & \multicolumn{2}{|c|}{ SROTP (males per 100 females) } & 0.21 & 0.122 & 0.28 & 0.036 & 0.30 & 0.026 & 0.25 & 0.067 & 0.36 & 0.007 \\
\hline & \multicolumn{2}{|l|}{ Median age } & -0.01 & 0.940 & -0.05 & 0.714 & 0.35 & 0.008 & -0.11 & 0.432 & 0.28 & 0.040 \\
\hline & \multirow[t]{3}{*}{ PTPbscbag } & $0-24$ & 0.04 & 0.756 & 0.07 & 0.627 & -0.35 & 0.010 & 0.09 & 0.506 & -0.29 & 0.034 \\
\hline & & $25-64$ & -0.04 & 0.748 & -0.06 & 0.671 & 0.36 & 0.008 & -0.07 & 0.613 & 0.31 & 0.023 \\
\hline & & $65+$ & 0.00 & 0.990 & -0.01 & 0.954 & 0.31 & 0.020 & -0.12 & 0.370 & 0.24 & 0.084 \\
\hline & \multirow[t]{3}{*}{ PMPbag } & $0-24$ & 0.04 & 0.785 & 0.51 & 0.711 & -0.34 & 0.012 & 0.07 & 0.619 & -0.29 & 0.032 \\
\hline & & $25-64$ & -0.04 & 0.769 & -0.05 & 0.714 & 0.35 & 0.010 & -0.06 & 0.650 & 0.30 & 0.025 \\
\hline & & $65+$ & 0.07 & 0.634 & 0.09 & 0.503 & 0.29 & 0.030 & 0.00 & 0.990 & 0.27 & 0.046 \\
\hline & \multirow[t]{3}{*}{ PFPbag } & $0-24$ & 0.05 & 0.722 & 0.07 & 0.603 & -0.33 & 0.014 & 0.11 & 0.415 & -0.26 & 0.060 \\
\hline & & $25-64$ & -0.05 & 0.729 & -0.06 & 0.648 & 0.34 & 0.011 & -0.08 & 0.567 & 0.28 & 0.038 \\
\hline & & $65+$ & -0.01 & 0.971 & -0.05 & 0.741 & 0.30 & 0.025 & -0.21 & 0.132 & 0.20 & 0.152 \\
\hline \multirow{11}{*}{$\begin{array}{l}\text { Asia and } \\
\text { Oceania }\end{array}$} & SROTP (male & females) & 0.31 & 0.032 & 0.17 & 0.249 & 0.44 & 0.002 & -0.17 & 0.258 & 0.40 & 0.005 \\
\hline & Median age & & 0.33 & 0.022 & 0.21 & 0.144 & 0.35 & 0.014 & 0.09 & 0.555 & 0.30 & 0.036 \\
\hline & PTPbscbag & $0-24$ & -0.37 & 0.010 & -0.20 & 0.166 & -0.44 & 0.002 & -0.02 & 0.918 & -0.38 & 0.009 \\
\hline & & $25-64$ & 0.35 & 0.016 & 0.12 & 0.408 & 0.52 & $1.475 \times 11$ & -0.14 & 0.343 & 0.38 & 0.007 \\
\hline & & $65+$ & 0.05 & 0.744 & 0.13 & 0.367 & -0.17 & 0.251 & 0.30 & 0.035 & -0.15 & 0.325 \\
\hline & PMPbag & $0-24$ & -0.39 & 0.007 & -0.20 & 0.171 & -0.50 & $2.688 \times 11$ & 0.03 & 0.860 & -0.43 & 0.002 \\
\hline & & $25-64$ & 0.35 & 0.014 & 0.14 & 0.350 & 0.51 & $1.943 \times 11$ & -0.12 & 0.406 & 0.40 & 0.004 \\
\hline & & $65+$ & 0.06 & 0.673 & 0.15 & 0.302 & -0.17 & 0.247 & 0.32 & 0.029 & -0.13 & 0.365 \\
\hline & PFPbag & $0-24$ & -0.28 & 0.052 & -0.19 & 0.206 & -0.29 & 0.048 & -0.11 & 0.454 & -0.23 & 0.114 \\
\hline & & $25-64$ & 0.32 & 0.025 & 0.12 & 0.404 & 0.42 & 0.003 & -0.07 & 0.627 & 0.28 & 0.056 \\
\hline & & $65+$ & 0.02 & 0.873 & 0.10 & 0.504 & -0.16 & 0.284 & 0.28 & 0.052 & -0.14 & 0.330 \\
\hline Americas & SROTP (male & females) & -0.10 & 0.599 & -0.13 & 0.483 & -0.10 & 0.568 & -0.13 & 0.462 & -0.18 & 0.319 \\
\hline & Median age & & 0.03 & 0.891 & -0.02 & 0.904 & 0.17 & 0.333 & 0.03 & 0.872 & 0.19 & 0.285 \\
\hline & PTPbscbag & $0-24$ & -0.04 & 0.838 & 0.01 & 0.944 & -0.18 & 0.309 & -0.03 & 0.891 & -0.19 & 0.028 \\
\hline & & $25-64$ & -0.05 & 0.793 & -0.10 & 0.579 & 0.09 & 0.610 & 0.02 & 0.897 & 0.13 & 0.470 \\
\hline & & $65+$ & 0.12 & 0.517 & 0.04 & 0.822 & 0.25 & 0.164 & -0.11 & 0.534 & 0.16 & 0.365 \\
\hline & PMPbag & $0-24$ & -0.04 & 0.825 & 0.02 & 0.899 & -0.18 & 0.317 & 0.01 & 0.979 & -0.18 & 0.323 \\
\hline & & $25-64$ & -0.05 & 0.802 & -0.11 & 0.554 & 0.08 & 0.653 & -0.01 & 0.963 & 0.11 & 0.532 \\
\hline & & $65+$ & 0.10 & 0.573 & 0.02 & 0.926 & 0.24 & 0.177 & -0.13 & 0.484 & 0.15 & 0.397 \\
\hline & PFPbag & $0-24$ & -0.05 & 0.789 & 0.00 & 0.991 & -0.18 & 0.319 & -0.02 & 0.915 & -0.20 & 0.287 \\
\hline & & $25-64$ & -0.13 & 0.483 & -0.17 & 0.339 & 0.01 & 0.937 & 0.03 & 0.885 & 0.07 & 0.718 \\
\hline & & $65+$ & 0.14 & 0.445 & 0.07 & 0.705 & 0.26 & 0.144 & -0.10 & 0.570 & 0.17 & 0.349 \\
\hline
\end{tabular}

COVID-19 coronavirus disease 2019, SROTP sex ratio of the total population, PTPbscbag percentage of total population, both sexes combined, by broad age group, PMPbag percentage of male population by broad age group, PFPbag percentage of female population by broad age group 
Table 3 Correlation between composition of age and gender in high and non-high income countries/territories and epidemic characteristics of COVID-19

\begin{tabular}{|c|c|c|c|c|c|c|c|c|c|c|c|c|}
\hline \multirow[t]{2}{*}{ Regions } & \multirow{2}{*}{\multicolumn{2}{|c|}{$\begin{array}{l}\text { Composition of age } \\
\text { and gender }\end{array}$}} & \multicolumn{2}{|c|}{$\begin{array}{l}\text { Total number of } \\
\text { cases }\end{array}$} & \multicolumn{2}{|c|}{$\begin{array}{l}\text { Total number of } \\
\text { deaths }\end{array}$} & \multicolumn{2}{|c|}{$\begin{array}{l}\text { Incidence rate of } \\
\text { COVID-19 }\end{array}$} & \multicolumn{2}{|c|}{$\begin{array}{l}\text { Case fatality rate of } \\
\text { COVID-19 }\end{array}$} & \multicolumn{2}{|c|}{$\begin{array}{l}\text { Mortality rate of } \\
\text { COVID- } 19\end{array}$} \\
\hline & & & $R_{S}$ & $p$ & $R_{S}$ & $p$ & $R_{S}$ & $p$ & $R_{S}$ & $p$ & $R_{S}$ & $p$ \\
\hline \multirow[t]{11}{*}{$\begin{array}{l}\text { High-income coun- } \\
\text { tries/territories }\end{array}$} & \multicolumn{2}{|c|}{$\begin{array}{l}\text { SROTP (males per } 100 \\
\text { females) }\end{array}$} & 0.14 & 0.331 & -0.16 & 0.256 & 0.40 & 0.004 & -0.57 & $<0.0001$ & -0.18 & 0.196 \\
\hline & \multicolumn{2}{|l|}{ Median age } & 0.16 & 0.254 & 0.40 & 0.003 & -0.11 & 0.443 & 0.47 & $<0.001$ & 0.29 & 0.041 \\
\hline & \multirow[t]{3}{*}{ PTPbscbag } & $0-24$ & -0.20 & 0.148 & -0.27 & 0.053 & -0.01 & 0.956 & -0.20 & 0.154 & -0.09 & 0.516 \\
\hline & & $25-64$ & -0.05 & 0.726 & -0.28 & 0.041 & 0.09 & 0.520 & -0.43 & 0.002 & -0.35 & 0.012 \\
\hline & & $65+$ & 0.42 & 0.294 & 0.45 & 0.001 & -0.12 & 0.403 & 0.58 & $<0.0001$ & 0.41 & 0.003 \\
\hline & \multirow[t]{3}{*}{ PMPbag } & $0-24$ & -0.25 & 0.070 & -0.17 & 0.234 & -0.16 & 0.247 & 0.05 & 0.746 & 0.03 & 0.822 \\
\hline & & $25-64$ & -0.02 & 0.867 & -0.24 & 0.089 & 0.11 & 0.448 & -0.43 & 0.001 & -0.33 & 0.018 \\
\hline & & $65+$ & 0.26 & 0.065 & 0.54 & $<0.0001$ & 0.02 & 0.887 & 0.62 & $<0.0001$ & 0.49 & $<0.001$ \\
\hline & \multirow[t]{3}{*}{ PFPbag } & $0-24$ & -0.07 & 0.604 & -0.29 & 0.035 & 0.18 & 0.193 & -0.40 & 0.003 & -0.17 & 0.242 \\
\hline & & $25-64$ & -0.04 & 0.316 & -0.34 & 0.014 & 0.03 & 0.850 & -0.27 & 0.053 & -0.30 & 0.031 \\
\hline & & $65+$ & 0.11 & 0.433 & 0.42 & 0.002 & -0.16 & 0.262 & 0.55 & $<0.0001$ & 0.36 & 0.009 \\
\hline \multirow[t]{11}{*}{$\begin{array}{l}\text { Non-high-income } \\
\text { countries/territories }\end{array}$} & \multicolumn{2}{|c|}{$\begin{array}{l}\text { SROTP (males per } 100 \\
\text { females) }\end{array}$} & -0.06 & 0.499 & -0.02 & 0.865 & -0.06 & 0.500 & 0.06 & 0.501 & -0.04 & 0.634 \\
\hline & \multicolumn{2}{|l|}{ Median age } & 0.31 & 0.001 & 0.29 & 0.001 & 0.48 & $<0.0001$ & 0.06 & 0.498 & 0.41 & $<0.0001$ \\
\hline & \multirow[t]{3}{*}{ PTPbscbag } & $0-24$ & -0.30 & 0.001 & -0.28 & 0.002 & -0.49 & $<0.0001$ & -0.06 & 0.512 & -0.42 & $<0.0001$ \\
\hline & & $25-64$ & 0.28 & 0.001 & 0.25 & 0.006 & 0.46 & $<0.0001$ & 0.04 & 0.686 & 0.39 & $<0.0001$ \\
\hline & & $65+$ & 0.33 & $<0.001$ & 0.32 & $<0.001$ & 0.48 & $<0.0001$ & 0.08 & 0.392 & 0.43 & $<0.0001$ \\
\hline & \multirow[t]{3}{*}{ PMPbag } & $0-24$ & -0.29 & 0.001 & -0.27 & 0.002 & -0.49 & $<0.0001$ & -0.06 & 0.483 & -0.43 & $<0.0001$ \\
\hline & & $25-64$ & 0.27 & 0.002 & 0.24 & 0.007 & 0.47 & $<0.0001$ & 0.04 & 0.694 & 0.39 & $<0.0001$ \\
\hline & & $65+$ & 0.36 & $<0.001$ & 0.34 & $<0.001$ & 0.47 & $<0.0001$ & 0.11 & 0.209 & 0.43 & $<0.0001$ \\
\hline & \multirow[t]{3}{*}{ PFPbag } & $0-24$ & -0.31 & $<0.001$ & -0.28 & 0.001 & -0.48 & $<0.0001$ & -0.05 & 0.549 & -0.41 & $<0.0001$ \\
\hline & & $25-64$ & 0.28 & 0.002 & 0.25 & 0.006 & 0.45 & $<0.0001$ & 0.04 & 0.694 & 0.37 & $<0.0001$ \\
\hline & & $65+$ & 0.32 & $<0.001$ & 0.30 & 0.001 & 0.48 & $<0.0001$ & 0.05 & 0.612 & 0.42 & $<0.0001$ \\
\hline
\end{tabular}

COVID-19 coronavirus disease 2019, SROTP sex ratio of the total population, PTPbscbag percentage of total population, both sexes combined, by broad age group, PMPbag percentage of male population by broad age group, PFPbag percentage of female population by broad age group

correlated to PTPbscbag $(0-24)\left(r_{s}=-0.44, p=0.002\right.$; $r_{s}=-0.38, p=0.009$, respectively), and positively correlated to PTPbscbag (25-64) $\quad\left(r_{s}=0.52, \quad p<0.001\right.$; $r_{s}=0.38, p=0.007$, respectively), and PMPbag (25-64) $\left(r_{s}=0.51, \quad p<0.001 ; r_{s}=0.40, \quad p=0.004\right.$, respectively). Also, TC, IRC, and MRC were negatively correlated to PMPbag (0-24) $\left(r_{s}=-0.39, p=0.007 ; r_{s}=-0.50, p<0.001\right.$; $r_{s}=-0.43, p=0.002$, respectively). As for the female population, we found that only PFPbag (25-64) was positively correlated to IRC ( $\left.r_{s}=0.42, p=0.003\right)$, and no other significant correlation was observed. Additionally, no significant correlation exists among variables in the Americas ( $p>0.01$ for all).

\section{Correlations between the composition of age and} gender and the epidemic characteristics of COVID19 in high and non-high-income countries/territories

Table 3 illustrates the correlations between the age and gender distribution and the epidemic characteristics of COVID-19 (TC, TD, IRC, CFRC and MRC) in high and non-high income countries/territories. In countries/territories with high income, we found the SROTP (males per 100 females) was positively correlated to IRC $\left(r_{s}=0.40, p=0.004\right)$, and negatively correlated to CFRC $\left(r_{s}=-0.58, p<0.0001\right)$, While the median age was positively correlated to $\mathrm{TD}\left(r_{s}=0.40\right.$, $p=0.003)$, and CFRC $\left(r_{s}=0.47, p<0.001\right)$. We observed that TD, CFRC, and MRC were significantly correlated to PTPbscbag (65+) $\left(r_{s}=0.45, \quad p=0.001\right.$; $r_{s}=0.58, \quad p<0.0001 ; \quad r_{s}=0.41, p=0.003$, respectively). Among the male group, we noticed that CFRC, MRC were positively correlated to PMPbag (65+) $\left(r_{s}=0.62\right.$, $p<0.0001 ; r_{s}=0.50, p<0.001$; respectively), while CFRC was also negatively associated with PMPbag (25-64) $\left(r_{s}=-0.43, p=0.001\right)$. Besides, a positive correlation was detected between TD and PMPbag (65+) $\left(r_{s}=0.54\right.$, $p<0.0001)$. Among the female population, we discovered that CFRC was negatively correlated to PFPbag $(0-24)\left(r_{s}=-0.40, p=0.003\right)$, and positively correlated to PFPbag $(65+)\left(r_{s}=0.55, p<0.0001\right)$. We also detected positive correlations between PFPbag (65+), $\mathrm{TD}\left(r_{s}=0.42, p=0.002\right)$, and MRC $\left(r_{s}=0.36, p=0.009\right)$. Accordingly, higher correlations were observed between the ratio of people over 65 years old and CFRC, MRC in male group than in female group (male: $r_{s}=0.62, r_{s}=0.49$, respectively; female: $r_{s}=0.55$, $r_{s}=0.36$, respectively). Interestingly, no correlations were detected between IRC and all the age distribution indicators ( $p>0.01$ for all). 
Compared with high income countries/territories, we discovered dissimilar correlations in places with non-high income. No correlations exist among the SROTP (males per 100 females) and all the epidemic characteristics of COVID-19 (TC, TD, IRC, CFRC, and MRC), as well as among CFRC and all the age and gender distribution variables ( $p>0.01$ for all). Median age was found to be positively correlated to TC $\left(r_{s}=0.31, p=0.001\right)$, TD $\left(r_{s}=0.29, p=0.001\right)$, IRC $\left(r_{s}=0.48, p<0.0001\right)$, and $\operatorname{MRC}\left(r_{s}=0.41, p<0.0001\right)$. Besides, TC, TD, IRC, and MRC were negatively correlated to PTPbscbag (0-24) $\left(r_{s}=-0.30, p=0.001\right.$; $r_{s}=-0.28, \quad p=0.002 ; \quad r_{s}=-0.49, \quad p<0.0001 ; \quad r_{s}=-0.42$, $p<0.0001$, respectively), PMPbag $(0-24) \quad\left(r_{s}=-0.29\right.$, $p=0.001 ; \quad r_{s}=-0.27, \quad p=0.002 ; \quad r_{s}=-0.49, \quad p<0.0001$; $r_{s}=-0.43, \quad p<0.0001, \quad$ respectively), PFPbag (0-24) $\left(r_{s}=-0.31, \quad p<0.001 ; \quad r_{s}=-0.28, \quad p=0.001 ; \quad r_{s}=-0.48\right.$, $p<0.0001 ; \quad r_{s}=-0.41, \quad p<0.0001$, respectively), and positively correlated to PTPbscbag $(25-64) \quad\left(r_{s}=0.28\right.$, $p=0.001 ; r_{s}=0.25, p=0.006 ; r_{s}=0.46, p<0.0001 ; r_{s}=0.39$, $p<0.0001$, respectively), PMPbag (25-64) $\quad\left(r_{s}=0.27\right.$, $p=0.002 ; r_{s}=0.24, p=0.007 ; r_{s}=0.47, p<0.0001, r_{s}=0.39$, $p<0.0001$, respectively), PFPbag (25-64) $\quad\left(r_{s}=0.28\right.$, $p=0.002 ; r_{s}=0.25, p=0.006 ; r_{s}=0.45, p<0.0001 ; r_{s}=0.37$, $p<0.0001$, respectively). In addition, positive correlations were discovered among TC, TD, IRC, MRC and PTPbscbag (65+) $\left(r_{s}=0.33, r_{s}=0.32, r_{s}=0.48, r_{s}=0.43\right.$, respectively, $p<0.001$ for all), PMPbag (65+) $\left(r_{s}=0.36\right.$, $r_{s}=0.34, r_{s}=0.47, r_{s}=0.43$, respectively, $p<0.001$ for all), PFPbag (65+) $\left(r_{s}=0.32, p<0.001 ; r_{s}=0.30, p=0.001\right.$; $r_{s}=0.48, p<0.0001 ; r_{s}=0.42, p<0.0001$, respectively). Besides, the correlations among people aged over 65 years old and the IRC were higher among female than male group (male group: 0.47, female group: 0.48), while the correlations with MRC were lower in the female group (male: 0.43 , female: 0.42 ).

\section{Discussion}

To better respond to the pandemic of COVID-19, we cannot only place our hope on the vaccine or effective antiviral drug since it would take more than 1 year from the development of a vaccine to the substantial production of the vaccine [12]. Recognizing populations prone to COVID-19 and implementing strong and targeted interventions are also crucial for minimizing the impact of this pandemic and beneficial for the control of COVID-19. The current study indicated that TRC, CFRC, and MRC were highly associated with the ratio of people over 65 years of age. On the contrary, places with a higher proportion of junior people (under 25 years old) are less prone to COVID-19, with a lower incidence rate, case fatality rate, and mortality rate. Interestingly, we noticed that the ratio of people over 65 years old was positively associated with IRC, with a higher correlation in females than in males. Inversely, the correlations between the ratio of older (over 65 years old) and MRC well as CFRC were lower among female groups. Besides, we discovered the age- gender-dependent differences were highly associated with CFRC in countries/territories with high income, and in places with non-high income, such significant correlations were detected among the age-gender-distribution and IRC.

As observed in the current study, the median age was strongly associated with IRC, CFRC, and MRC. Since the outbreak of COVID-19, most countries and territories had implemented strong social distancing and self-quarantine instructions. Moreover, most people aged under 25 years old are students, who were required to take their school lessons online at home, while those over 25 years old had lower rates of compliance with the social distancing and quarantine requirements issued by local health authorities [7]. As a result, the higher the ratio of the people over 25 years, the higher the incidence rate of COVID-19. Since those who do not obey the quarantine rules are more likely to be exposed to the environment with a high risk of infection.

Age stands as one of the risk factors of diseases, plays an essential role in the severity and mortality of infectious diseases [13, 14]. Previous studies had identified that age $\geq 65$ years is one of the risk factors that predicting the mortality of COVID-19 patients [14]. The current research also showed that the higher the ratio of older people (aged over 65 years), the higher the case fatality rate and mortality rate of COVID-19. There is evidence that specific changes are processed during the infection period in the pulmonary pathology and function of when people are getting old [15]. Previous studies in macaques infected with SARS discovered that robust host innate responses to the virus, accompanied by the increase of differential inflammatory gene expression, and the decrease of interferon-beta (I) expression, were stronger in older macaques compared with the younger adults [16]. Besides, researchers had found that the level of lymphocytes is abnormally decreased in patients confirmed with SARS and COVID-19, whereas such a level is generally increased when facing common infectious diseases [17, 18]. Compared with young adults, the level of lymphocytes in older patients presented with a significantly lower level, which might also be a vital indicator of the severity of COVID-19 in older patients [19]. Besides these immune differences among older and younger people, the pre-existing conditions, such as obesity, drinking, smoking, and other unhealthful lifestyles, also contribute to the increased mortality of COVID-19, while these unhealthy habits are most commonly seen in the older group [20]. Therefore, more attention is required from the public to protect the older people from the virus, and aggressive early intervention should be implemented to improve their prognosis, minimizing the harmful consequences caused by SARS-CoV-2. In addition, the correlation between people aged between 25-64 and the MRC in countries/territories with high income was negative, while in places with non-high income, these 
two variables were positively correlated. This might be because the healthcare system in those places is undeveloped and fragile compared with high-income countries [21]. Such differences in the healthcare system may also contribute to the age-gender-associated differentiation of IRC and CFRC, calling for more investments and global attention to the healthcare system in countries/territories with low and middle income to improve population health.

Another determinant factor of health is gender [22]. Recent studies emphasized that women are more likely to be infected by COVID-19; however, severe and fatal outcomes are more commonly seen among male patients [9]. Current research observed that a higher correlation existed between the ratio of people over 65 years old and IRC in females than in males. Moreover, the correlations among the ratio of older people, MRC, and CFRC were higher among male groups. Previously research has shown that women were more likely to be infected with the Ebola virus, which spread across West Africa from 2014 to 2016, given that females usually serve as care providers in families and communities [23]. Researchers have discovered that one of the gateways for the SARS$\mathrm{CoV}-2$ entry to tissues is the angiotensin-converting enzyme 2 (ACE2) receptor, which is located on the X chromosome [24, 25]. Therefore, females presented with a higher level of ACE2. Consequently, they are more susceptible to COVID-19 compared to males. As a result, females need to pay more attention to selfprotecting controls to stay away from SARS-CoV-2.

It is reported that the male predominance phenomena of COVID-19 might be due to the androgendriven pathogen of SARS-CoV-2 [26]. In contrast, estrogen can increase the Interferon-gamma (IFN$\gamma$ ) promoter's activity, which participates in the responses to viral pathogens [27]. Besides, a higher level of IgG antibody, which could help against SARSCoV-2, was observed in female patients compared with males [28], and more immune-related genes were located on X-chromosome [29]. All the evidence suggested that women possess a stronger adaptive immune response than males. Therefore, extra attention is required to male patients, particularly those over 65 years old in high-income countries/territories and those over 25 years old in places with non-high income for enhanced clinical management.

\section{Strengths and limitations}

This is the first study exploring the association between the epidemic characteristics of COVID-19 and the composition of age and gender among the total population across a wide range of countries and territories; however, some potential limitations needed to be recognized. First, we did not include all the places affected by COVID-19; only 177 countries/ territories were included in the current study (as of 31 May 2020, 188 countries/territories have been affected by COVID-19). Second, the detailed information of COVID-19 patients such as age and gender are not available from JHU; further analysis remains impossible. Besides, additional studies are required to understand the mechanisms of our observed agegender-associated differentiations in the epidemic of COVID-19.

\section{Conclusion}

Current research raises awareness about the age-gender-associated differences in the IRC, CFRC, and MRC. Of interest, the age-related correlation with IRC was higher in females, while the correlation between age distribution and CFRC as well as MRC was higher in males. The age-gender-dependent differences were significantly correlated to IRC in places with high income and associated with CFRC in non-high income countries/territories. Such age-gender-dependent differentiations imply that females need to strengthen their vigilance to take more effective self-protecting measures to stay away from the virus. Our results also suggest that more attention is needed to be paid to male patients, particularly those over 65 years old, for enhanced clinical management, and more investments are required to upgrade the healthcare system in countries/territories with non-high income to improve population health.

Supplementary Information The online version of this article (https://doi.org/10.1007/s00508-021-01816-z) contains supplementary material, which is available to authorized users.

Acknowledgements We thank all the people who offer help for this study.

Author Contribution FW conceived the study idea. DH collected the data. XL, NM, ZL, YT, FZ, and FW contributed to the analysis of the data. DH, and XL wrote the initial draft with all authors providing critical feedback and edits to subsequent revisions. All authors approved the final draft of the manuscript. All authors are accountable for all aspects of the work in ensuring that questions related to the accuracy or integrity of any part of the work are appropriately investigated and resolved. FW is the guarantor. The corresponding author attests that all listed authors meet authorship criteria and that no others meeting the criteria have been omitted.

Conflict of interest D. Hu, X. Lou, N. Meng, Z. Li, Y. Teng, Y. Zou and F. Wang declare that they have no competing interests.

\section{References}

1. Poutanen SM, Low DE. Severe acute respiratory syndrome: an update. CurrOpin InfectDis. 2004;17(4):287-94. https:// doi.org/10.1097/01.qco.0000136924.45049.7e. PMID: 15241071 .

2. Mena I, Nelson MI, Quezada-Monroy F, et al. Origins of the 2009 H1N1 influenza pandemic in swine in Mexico. Elife. 2016;5:e16777. https://doi.org/10.7554/eLife.16777.

3. Mackay IM, Arden KE. MERS coronavirus: diagnostics, epidemiology and transmission. Virol J. 2015;12:222. https:// doi.org/10.1186/s12985-015-0439-5. 
4. $\mathrm{Xu} \mathrm{X}, \mathrm{Yu} \mathrm{C}, \mathrm{Qu} J$, et al. Imaging and clinical features of patients with 2019 novel coronavirus SARS-CoV-2. Eur J Nucl Med Mol Imaging. 2020;47(5):1275-80. https://doi. org/10.1007/s00259-020-04735-9.

5. COVID-19 Dashboard by the Center for Systems Science and Engineering (CSSE) at Johns Hopkins University (JHU).. https: / /www.arcgis.com/apps/opsdashboard/ index.html\#/bda7594740fd40299423467b48e9ecf6. Accessed 31 May 2020.

6. Chen N, Zhou M, Dong X, et al. Epidemiological and clinical characteristics of 99 cases of 2019 novel coronavirus pneumonia in Wuhan, China: a descriptive study. Lancet. 2020;395(10223):507-13. https://doi.org/10.1016/S01406736(20)30211-7.

7. DudleyJP, LeeNT. Disparities in Age-Specific Morbidity and Mortality from SARS-CoV-2 in China and the Republic of Korea. Clin Infect Dis. 2020;31:ciaa354. https:// doi.org/10. 1093/ cid/ciaa354.

8. Jin JM, Bai P, HeW, et al. Gender differences in patients with COVID-19: focus on severity and mortality. Front Public Health. 2020;8:152. https://doi.org/10.3389/fpubh.2020. 00152.

9. Qian J, Zhao L, Ye RZ, Li XJ, Liu YL. Age-dependent gender differences of COVID-19 in mainland China: comparative study. Clin Infect Dis. 2020;30:ciaa683. https:// doi.org/10. 1093/ cid/ciaa683.

10. United Nations, Department of Economic and Social Affairs, Population Division. World population prospects 2019, Online edition. Rev. 1. 2019.

11. World Bank. World bank country and lending groups.. https://datahelpdesk.worldbank.org/knowledgebase/ articles/906519. Accessed31 May2020.

12. Anderson RM, HeesterbeekH, KlinkenbergD, Hollingsworth TD. How will country-based mitigation measures influence the course of the COVID-19 epidemic? Lancet. 2020;395(10228):931-4. https://doi.org/10.1016/S01406736(20)30567-5.

13. Zhou F, Yu T, Du R, et al. Clinical course and risk factors for mortality of adult inpatients with COVID-19 in Wuhan, China: a retrospective cohort study. Lancet. 2020;395(10229):1054-62. https://doi.org/10.1016/S01406736(20)30566-3. Erratum in: Lancet. 2020 March 28;395(10229):1038. Erratum in: Lancet. 2020 March 28;395(10229):1038.

14. Du RH, Liang LR, Yang CQ, et al. Predictors of mortality for patients with COVID-19 pneumonia caused by SARS-CoV-2: a prospective cohort study. Eur Respir J. 2020;55(5):2000524. https://doi.org/10.1183/13993003. 00524-2020.

15. Liu Y, Mao B, Liang S, et al. Association between age and clinical characteristics and outcomes of COVID-19 Eur Respir J. 2020;55(5):2001112. https://doi.org/10.1183/ 13993003.01112-2020.

16. Smits SL, de Lang A, van den Brand JM, et al. Exacerbated innate host response to SARS-CoV in aged non-human primates. PLoS Pathog. 2010;6(2):e1000756. https://doi. org/10.1371/journal.ppat.1000756.

17. He Z, Zhao C, Dong Q, et al. Effects of severe acute respiratory syndrome (SARS) coronavirus infection on peripheral blood lymphocytes and their subsets. J Infect Dis. 2005;9(6):323-30. https://doi.org/10.1016/j.ijid.2004. 07.014.

18. Zhang JJ, Dong X, Cao YY, et al. Clinical characteristics of 140 patients infected with SARS-CoV-2 in Wuhan, China. Allergy. 2020; https://doi.org/10.1111/all.14238.

19. Guan WJ, Ni ZY, Hu Y, et al. Clinical characteristics of Coronavirus disease 2019 in China. N Engl J Med. 2020;382(18):1708-20. https://doi.org/10.1056/ NEJMoa2002032.

20. LaucG, Sinclair D. Biomarkers of biological age as predictors of COVID-19 disease severity. Aging. 2020;12(8):6490-1. https://doi.org/10.18632/aging.103052.

21. Han W. Health care system reforms in developing countries. J Public Health Res. 2012;1(3):199-207. https://doi.org/10. 4081/jphr.2012.e31.

22. World Health Organization. Addressing sex and gender in epidemic-prone infectiousdiseases.. https://www.who. int/csr/resources/publications/SexGenderInfectDis.pdf? ua $=1$. Accessed 31 May 2020 .

23. Davies SE, Bennett B. A gendered human rights analysis of Ebola and Zika: locating gender in global health emergencies. Int Aff. 2016;92:1041-60.

24. Batlle D, Wysocki J, Satchell K. Soluble angiotensin-converting enzyme 2: a potential approach for coronavirus infection therapy? Clin Sci. 2020;134(5):543-5. https://doi. org/10.1042/CS20200163.

25. Bhatia K, Zimmerman MA, Sullivan JC. Sex differences in angiotensin-converting enzyme modulation of Ang (1-7) levels in normotensive WKY rats. Am J Hypertens. 2013;26(5):591-8. https://doi.org/10.1093/ajh/hps088.

26. Brenner SR. Covid-19, TMPRSS2, and whether android regulation affects pandemic virus genderincidence and age distribution of disease. Med Hypotheses. 2020;140:109773. https://doi.org/10.1016/j.mehy.2020.109773.

27. Marriott I, Huet-Hudson YM. Sexual dimorphism in innate immune responses to infectious organisms. Immunol Res. 2006;34(3):177-92. https://doi.org/10.1385/IR:34:3:177.

28. ZengF, Dai C, Cai P, etal. A comparison study of SARS-CoV-2 IgG antibody between male and female COVID-19 patients: A possible reason underlying different outcome between sex. J Med Virol. 2020; https:// doi.org/10.1002/jmv.25989.

29. Schurz H, Salie M, Tromp G, Hoal EG, Kinnear CJ, Möller M. The $\mathrm{X}$ chromosome and sex-specific effects in infectious disease susceptibility. Hum Genomics. 2019;13(1):2. https://doi.org/10.1186/s40246-018-0185-z.

Publisher's Note Springer Nature remains neutral with regard to jurisdictional claims in published maps and institutional affiliations. 